\title{
Angiotensin II sustains brain inflammation in mice via TGF- $\beta$
}

\author{
Tobias V. Lanz,, ${ }^{1,2}$ Zhaoqing Ding, ${ }^{1}$ Peggy P. Ho, ${ }^{1}$ Jian Luo, ${ }^{1}$ Ankur N. Agrawal, ${ }^{1}$ \\ Hrishikesh Srinagesh, ${ }^{1}$ Robert Axtell, ${ }^{1}$ Hui Zhang, ${ }^{1}$ Michael Platten, ${ }^{2}$ \\ Tony Wyss-Coray, ${ }^{1,3}$ and Lawrence Steinman ${ }^{1}$
}

\begin{abstract}
${ }^{1}$ Department of Neurology and Neurological Sciences, Stanford University School of Medicine, Stanford, California, USA. 2Department of Neurooncology, University Hospital Heidelberg, and German Cancer Research Center, Heidelberg, Germany. ${ }^{3}$ Geriatric Research Education and Clinical Center, VA Palo Alto Health Care System, Palo Alto, California, USA.
\end{abstract}

\begin{abstract}
The renin-angiotensin-aldosterone system (RAAS) is a key hormonal system regulating blood pressure. However, expression of RAAS components has recently been detected in immune cells, and the RAAS has been implicated in several mouse models of autoimmune disease. Here, we have identified Ang II as a paracrine mediator, sustaining inflammation in the CNS in the EAE mouse model of MS via TGF- $\beta$. Ang II type 1 receptors (AT1Rs) were found to be primarily expressed in CNS-resident cells during EAE. In vitro, astrocytes and microglia responded to Ang II treatment by inducing TGF- $\beta$ expression via a pathway involving the TGF- $\beta$-activating protease thrombospondin-1 (TSP-1). TGF- $\beta$ upregulation in astrocytes and microglia during EAE was blocked with candesartan (CA), an inhibitor of AT1R. Treatment of EAE with CA ameliorated paralysis and blunted lymphocyte infiltration into the CNS, outcomes that were also seen with genetic ablation of AT1Ra and treatment with an inhibitor of TSP-1. These data suggest that AT1R antagonists, frequently prescribed as antihypertensives, may be useful to interrupt this proinflammatory, CNS-specific pathway in individuals with MS.
\end{abstract}

\section{Introduction}

The renin-angiotensin-aldosterone system (RAAS) is a major endocrine system, regulating blood pressure and body fluid homeostasis. Angiotensin peptides not only act on the vasculature, heart, kidney, and adrenal gland but also in the brain to mediate these important functions. Renin cleaves off the decapeptide Ang I from the protein angiotensinogen. Angiotensin-converting enzyme (ACE) cleaves off 2 additional amino acids, resulting in the octapeptide Ang II, which is the main effector molecule, acting on its target cells via the $2 \mathrm{G}$ protein-coupled receptors, Ang II type 1 receptor (AT1R) and Ang II type 2 receptor. AT1R is responsible for most of the known effects of Ang II.

Recent studies have found several molecular components of this endocrine system in different tissues (1), such as the heart (2), pancreas (3), eye (4), brain (5), thymus (6), and immune cells (7-9). The proposed autocrine or paracrine RAAS-mediated mechanisms have been described in diverse diseases, such as fibrosis (2), atherosclerosis $(8,10)$, and inflammation $(7,11)$. But the exact functions and molecular mechanisms of these tissue-restricted RAASs are still not completely understood. In inflammation, it has been shown that Ang II acts on several levels. For instance, it fosters differentiation of dendritic cells from monocytes (7), and it stimulates neutrophil accumulation (11).

Several reports have further implicated a role for the RAAS in autoimmunity. The inhibition of ACE or AT1R in mouse models of rheumatoid arthritis attenuates clinical symptoms and modulates $\mathrm{T}$ cell cytokine profiles $(12,13)$. Treatment with the AT1R inhibitor telmisartan is beneficial in experimental autoimmune

Authorship note: Tobias V. Lanz, Zhaoqing Ding, and Peggy P. Ho contributed equally to this work.

Conflict of interest: The authors have declared that no conflict of interest exists. Citation for this article: J Clin Invest. 2010;120(8):2782-2794. doi:10.1172/JCI41709. uveoretinitis in mice (14). We recently demonstrated that treatment with ACE inhibitors ameliorates relapsing-remitting EAE, the proteolipid protein 139-151 peptide-induced ( $\mathrm{PLP}_{139-151^{-}}$ induced) SJL mouse model of relapsing-remitting MS. We further showed that ACE inhibitors suppress inflammatory Th1 and Th17 cells and induce Tregs in SJL mice (15).

TGF- $\beta$ is a multipotent cytokine secreted by a variety of different cell types. It is involved in inflammation, cell growth, apoptosis, and matrix synthesis (16). In inflammation, TGF- $\beta$ plays a Januslike dual role on $T$ cells, as it contributes both to the induction of beneficial immunosuppressive Tregs and to the harmful skewing of T cells toward inflammatory Th17 cells (17). The role of TGF- $\beta$ is therefore determined by the context of the surrounding milieu, namely the accompanying cytokines and the location at which $\mathrm{T}$ cells are stimulated. We have shown previously that TGF- $\beta$ signaling is vastly upregulated in the CNS before and during the onset of chronic-progressive EAE, the myelin oligodendrocyte glycoprotein 35-55 peptide-induced ( $\mathrm{MOG}_{35-55}-$ induced) $\mathrm{C} 57 \mathrm{BL} / 6$ mouse model of chronic-progressive MS (18). Here, TGF- $\beta$ creates a permissive environment for inflammation. Treatment with a pharmacological inhibitor of the TGF- $\beta$ receptor I (TGF- $\beta$ RI) resulted in a delay of onset and mitigation of the disease.

TGF- $\beta$, which is secreted as an inactive proprotein, can be activated by cleavage from its latency-associated protein (LAP) by a number of different molecules, including proteases, integrins, and thrombospondin-1 (TSP-1) (19). TSP-1 is a secreted multifunctional trimeric protein that has been shown to be upregulated by Ang II in different tissues, like the heart, kidney (20), and muscle (21). Transgenic TSP-1-knockout mice show a partial phenotypic overlap with TGF- $\beta$-knockout mice, thereby supporting the contention that TSP-1 is an important in vivo activator of latent TGF- $\beta$ (22). Proteomic analysis of brain lesions from MS patients demonstrates that TSP-1 is produced in high abundance in chronic active plaques (23). 

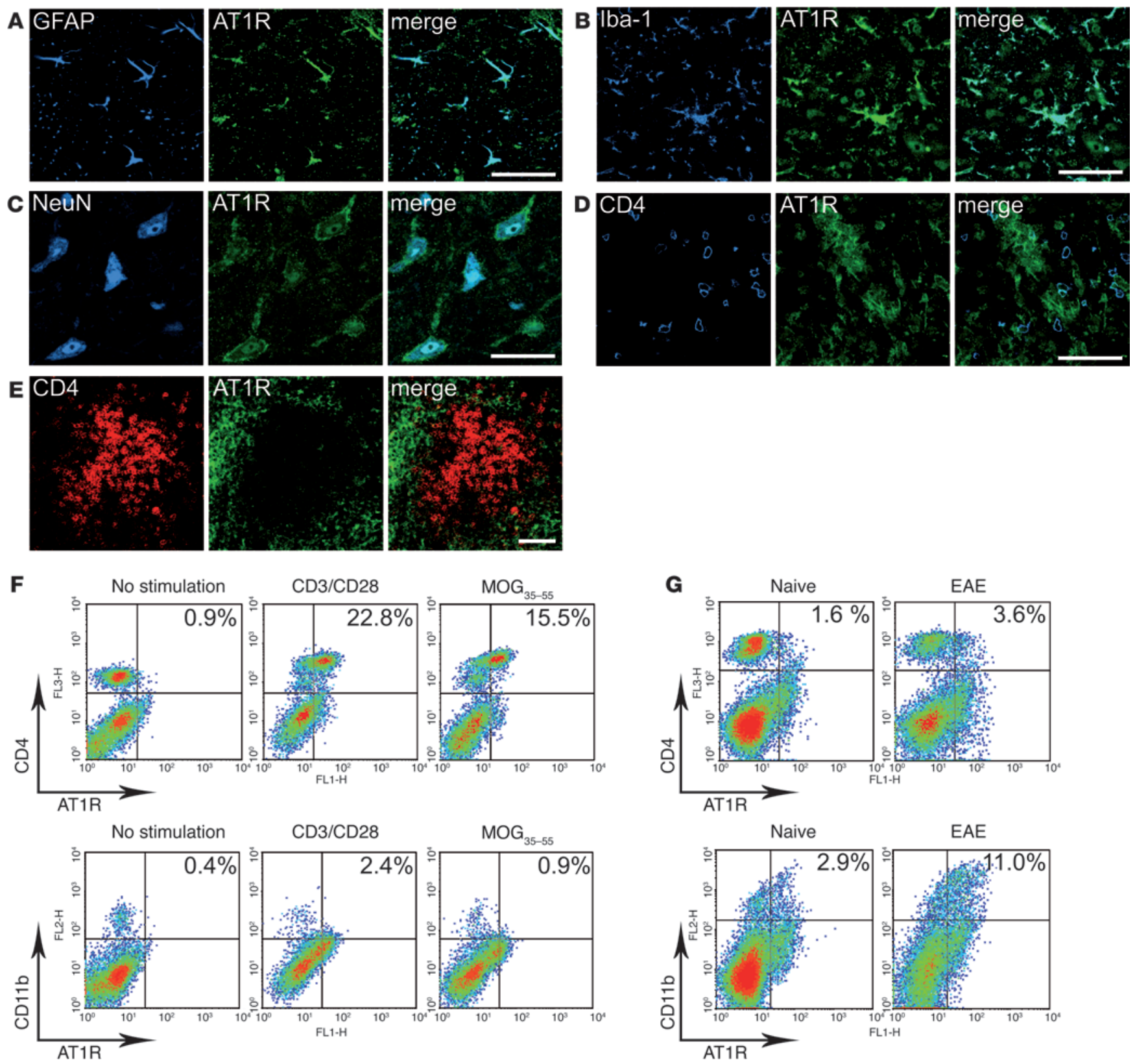

Figure 1

AT1R expression in CNS cells and immune cells. (A-D) Fluorescence double staining of spinal cords from diseased mice for AT1R (green) and the following specific cell markers (blue): (A) GFAP for astrocytes, (B) lba-1 for microglia, (C) NeuN for neurons, and (D) CD4 for CD4+ T cells. AT1R is highly expressed in astrocytes, microglia, and neurons, while it is almost not detectable in CD4+ $\mathrm{T}$ cells by immunohistochemistry, as surrounding CNS cells supersede T cells in immunoreactivity. (E) Fluorescence double staining of the spleen from a diseased mouse for CD4 (red) and AT1R (green). Immunoreactivity for AT1R is not detectable in $\mathrm{CD} 4^{+}$cells. All tissues were taken from vehicle control mice on day 6 after onset of EAE. Scale bars: $50 \mu \mathrm{m}$. (F) Cell surface AT1R expression in $\mathrm{CD}^{+}$and $\mathrm{CD} 11 \mathrm{~b}^{+}$splenocytes stimulated in vitro. Cells from naive $2 \mathrm{D} 2$ mice were stimulated in vitro with either $\mathrm{MOG}_{35-55}$ or anti-CD3/CD28 for 48 hours and then analyzed by FACS. Expression of AT1R increases on both cell types after antigen specific and nonspecific T cell stimulation. (G) Cell surface AT1R expression on CD4+ and CD11 b+ cells after induction of EAE. Splenocytes were taken on day 15 after immunization and analyzed by FACS. Expression of AT1R increases in both cell types after inducing neuroinflammation. FACS data are representative for at least 2 independent experiments. ( $\mathbf{F}$ and $\mathbf{G}$ ) The percentages of double positively stained cells are indicated in each box.

Recently, it has been shown that TSP-1-knockout mice are less susceptible to the induction of chronic-progressive EAE (24).

We describe here a remarkable interplay between the CNS and the immune system, with the RAAS acting on resident brain cells and on immune cells, modulating harmful autoimmunity in the brain.
During neuroinflammation, TGF- $\beta$ as well as TSP-1 are upregulated in astrocytes, microglia, and neurons, leading to increased TGF- $\beta$ signaling in the CNS during the early stages of EAE. This increase is abrogated by AT1R inhibitors and accompanied by delayed onset and attenuation of chronic-progressive $\mathrm{MOG}_{35-55}$-induced EAE. 

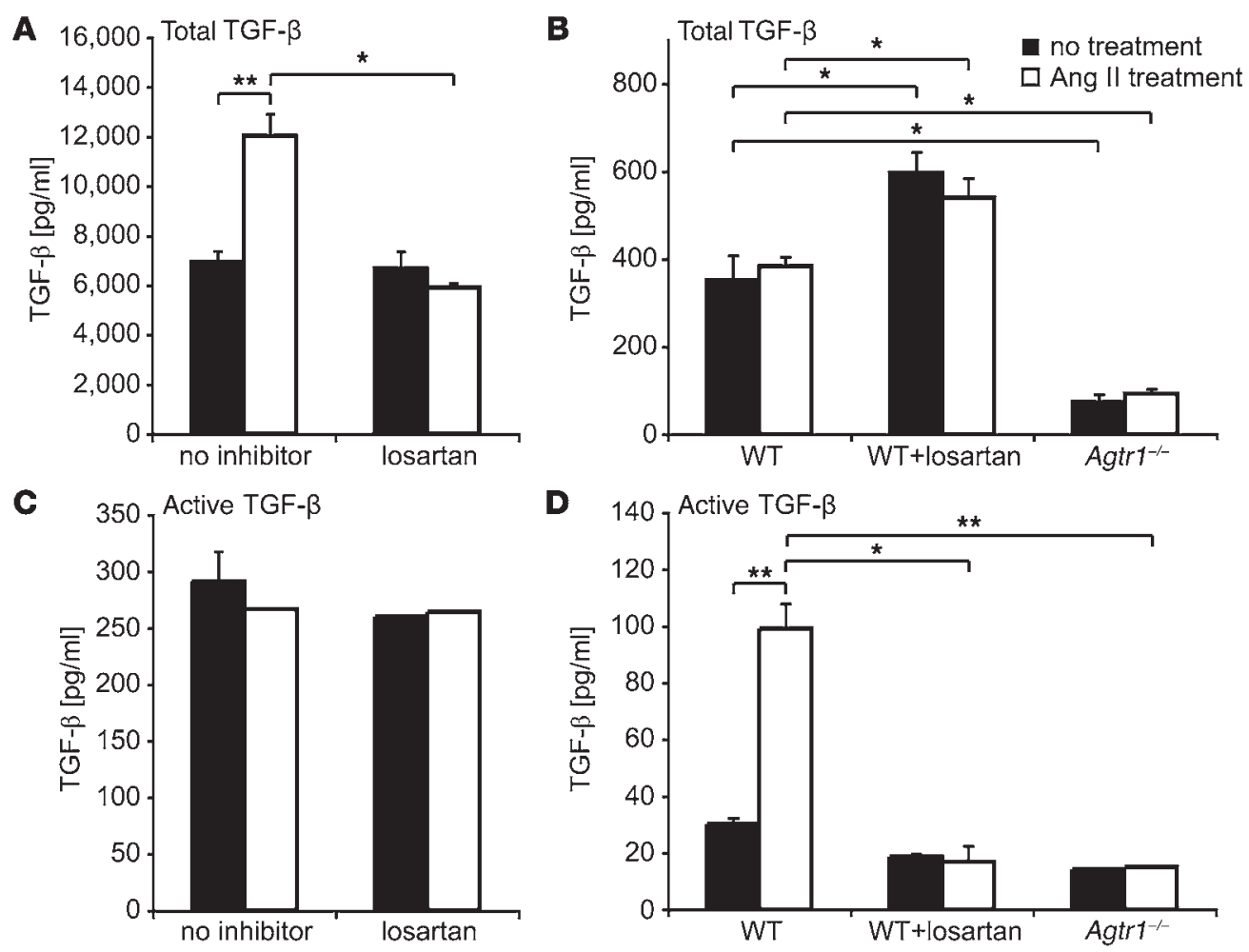

Figure 2

Ang II stimulates TGF- $\beta$ production and activation in primary cultured astrocytes and microglia. (A and B) Total TGF- $\beta$ in supernatants of primary cultured cells. (A) In microglial cells, total production of TGF- $\beta$ can be almost doubled by stimulation with Ang II. This effect can be abrogated by inhibition of AT1R with losartan. (B) In contrast, astrocytes produce much less and do not upregulate total TGF- $\beta$ production upon Ang II stimulation. (C and D) Active TGF- $\beta$ in supernatants of primary cultured cells. (C) Ang II does not have any effect on activation of TGF- $\beta$ in microglia, as opposed to (D) astrocytes, which triple the amount of active TGF- $\beta$ in their supernatants upon Ang II stimulation. This effect is also AT1R dependent and can be disrupted by losartan and by knockout of AT1R. Representative data are shown from 1 of 2 independent experiments; measurements were carried out in triplicates (mean \pm SEM). ${ }^{*} P<0.05,{ }^{* *} P<0.01$ (Student's $t$ test).

\section{Results}

Increased AT1R expression in the inflamed brain occurs mainly on CNSresident cells. Recently, we showed effective treatment of relapsingremitting EAE with ACE inhibitors and AT1R blockers in SJL mice. We observed AT1R expression on lymphocytic meningeal infiltrates of diseased mice as well as on human MS plaques (15). Though we and others also showed that AT1R is expressed at low levels on naive T cells as well as on monocytic cells and is upregulated upon in vitro activation, the functional significance of increased AT1R expression in vivo by inflamed CNS-resident cells still remained unclear $(15,25)$.

Here, we addressed the role of increased AT1R expression in inflamed CNS-resident cells in a mouse model of chronic-progressive EAE that bears many hallmarks of the neurodegeneration seen in MS. Fluorescence immunohistochemistry of AT1R in CNS tissue of C57BL/6 mice with chronic EAE showed that AT1R is preferentially expressed in astrocytes (stained for glial fibrillary acidic protein [GFAP]), microglial cells (stained for ionized calcium-binding adapter molecule 1 [Iba-1]), and neurons (stained for neuronal nuclei [NeuN]) (Figure 1, A-C), which is in line with our previous findings in human MS plaques (15). AT1R expression was low in $\mathrm{CD}^{+}$ $\mathrm{T}$ cells infiltrating the brain (Figure 1D) as well as in $\mathrm{CD}^{+}$sple-
Cultured astrocytes and microglia are responsive to Ang II. We analyzed the response of AT1R-expressing CNS-resident cells to Ang II. TGF- $\beta$ is a key cytokine in autoimmunity, playing a Janus-like dual role in MS and EAE $(18,26,27)$. Since Ang II can induce TGF- $\beta$ in various tissues, such as the lung, kidney, and blood vessels $(2,21,28-32)$, we were interested in whether this pathway is also active in microglia and astrocytes. We separately measured the amount of total and active TGF- $\beta$ in serum-free supernatants of primary cultured microglia and astrocytes. For quantification of TGF- $\beta$ we used the TGF- $\beta$-responsive MFBF11 cell line, measuring secreted alkaline phosphatase (SEAP) as a surrogate (33). Ang II increased the total production of TGF- $\beta$ in microglial cells. This increase was abrogated completely by specifically inhibiting AT1R with the AT1R antagonist losartan (Figure 2A). In contrast, Ang II did not alter the total TGF- $\beta$ production in astrocyte cultures (Figure $2 \mathrm{~B}$ ). Of note, however, constitutive total TGF- $\beta$ levels were lower in primary astrocytes from AT1Ra-deficient mice (herein referred to as Agtr1 $1^{-1-}$ mice), indicating that the endogenous angiotensin pathway may drive TGF- $\beta$ production in astrocytes. Interestingly, stimulation with losartan increased production of TGF- $\beta$. When measuring activated TGF- $\beta$ in the supernatants, we found that Ang II did 

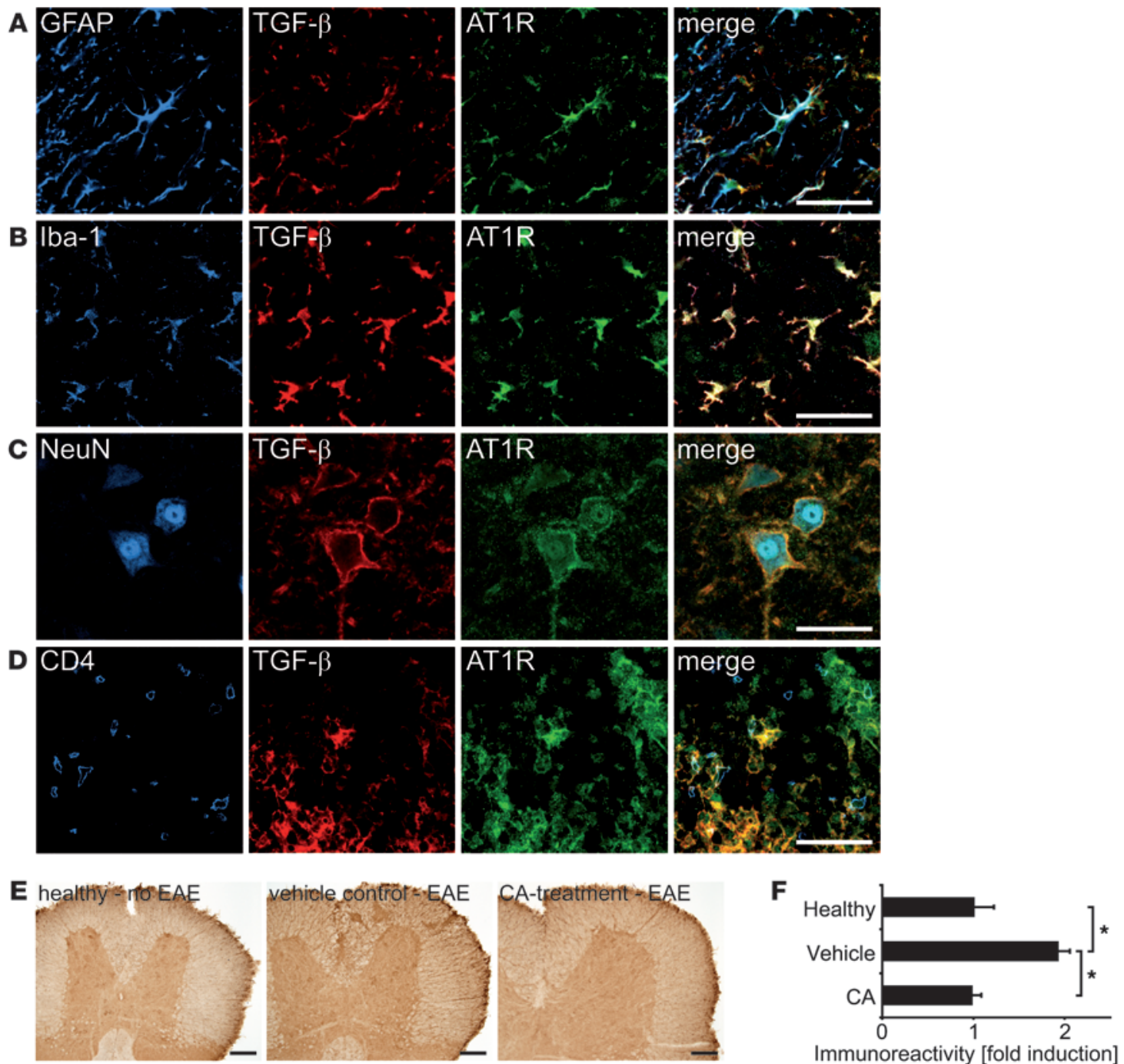

Figure 3

Ang II drives upregulation of TGF- $\beta$ during chronic EAE. (A-D) Fluorescence triple staining for TGF- $\beta$ (red), AT1R (green), and the following specific cellular markers (blue) as well as the merge of the 3 stainings: (A) astrocytes, (B) microglial cells, (C) neurons, and (D) CD4+ ${ }^{+}$cells. The merge shows expression of both AT1R and TGF- $\beta$ in astrocytes, microglia, and neurons. Scale bars: $50 \mu \mathrm{m}$. (E) Spinal cord slices stained for TGF- $\beta$. During EAE, TGF- $\beta$ is upregulated in the CNS compared with healthy mice. CA treatment suppresses TGF- $\beta$ expression. One representative slide of each group is shown. Scale bars: $100 \mu \mathrm{m}$. (F) Statistical evaluation of the experiment shown in E. TGF- $\beta$ staining intensities were evaluated with MetaMorph software and normalized on the healthy control group. Statistical analyses of 5 spinal cord slices per mouse are shown $\left(n=5\right.$ mice per group; mean \pm SEM). ${ }^{*} P<0.02$ (Student's $t$ test).

not influence the release of activated TGF- $\beta$ in microglial cells (Figure 2C). In contrast, stimulation with Ang II resulted in a marked increase of activated TGF- $\beta$ in astrocytes. Again, this augmentation could be reversed by adding losartan to the culture (Figure 2D). No change in TGF- $\beta$ production or activation levels was measured when using astrocytes from Agtr1 $1^{-1-}$ mice (Figure 2, B and D), confirming that this effect is mediated through AT1R. We had also considered a potential role for AT2R in TGF- $\beta$ production, but the use of an AT2R specific inhibitor, PD123319, did not support this hypothesis (data not shown). Collectively, these data indicated that microglial cells are the main Ang II-sensitive producers of TGF- $\beta$, while astrocytes respond to Ang II by inducing the activation of TGF- $\beta$.
TGF- $\beta$ is upregulated in the brain via Ang II. We next investigated the role of Ang II on TGF- $\beta$ expression in the CNS during chronic EAE. We have shown previously that TGF- $\beta$ is activated in the CNS during EAE and that CNS-specific TGF- $\beta$, as opposed to its antiinflammatory role in the peripheral adaptive immune system, sustains neuroinflammation by initiating influx of pathogenic $\mathrm{T}$ cells into the CNS (18). Fluorescence immunohistochemistry of TGF- $\beta$ in CNS tissue of C57BL/ 6 mice with chronic EAE showed that TGF- $\beta$ is expressed in astrocytes, microglial cells, and neurons but not in $\mathrm{CD} 4^{+} \mathrm{T}$ cells and that its expression colocalizes with AT1R (Figure 3, A-D), indicating a close spatial relation of the angiotensin and the TGF- $\beta$ pathway. To analyze the functional dependence of TGF- $\beta$ expression on endogenous 
A
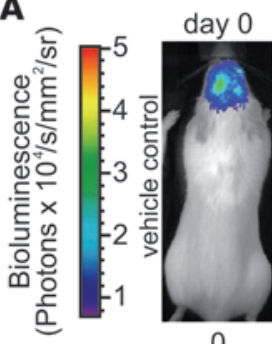

0

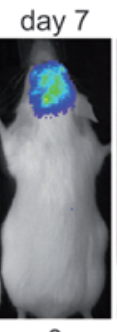

0

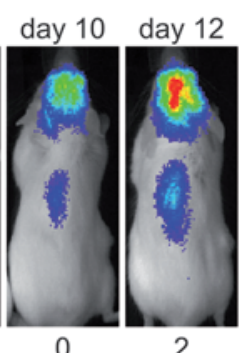

clinical score

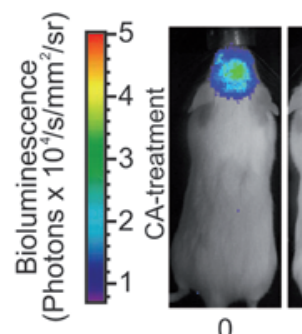

0

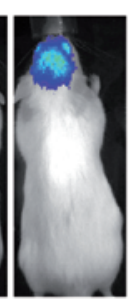

0

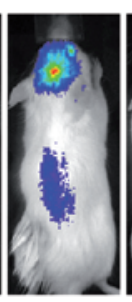

0

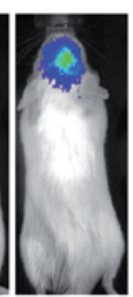

0 clinical score

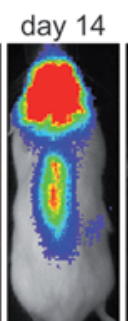

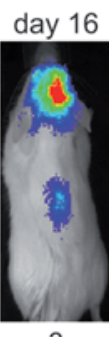

3

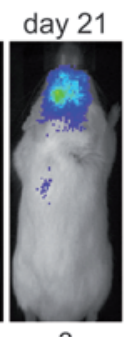

3

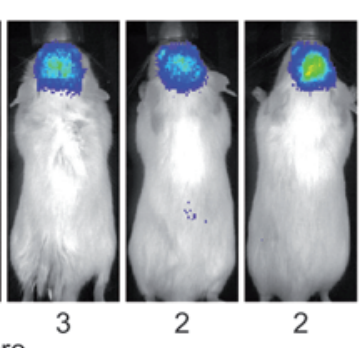

D

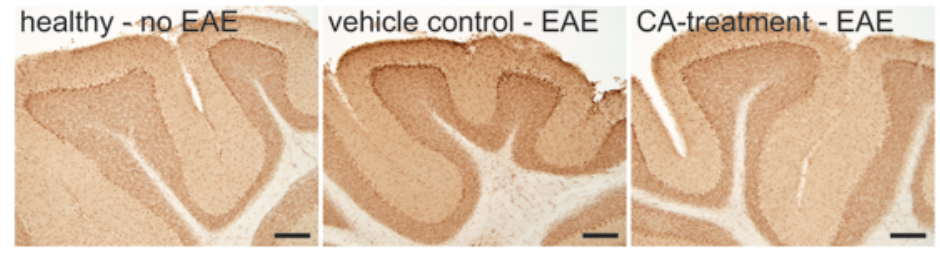

B

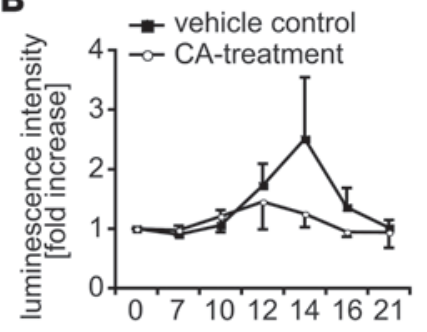

time after immunization [days]

C

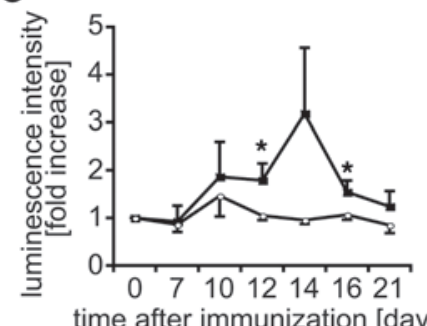

E

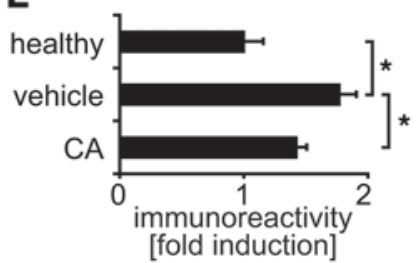

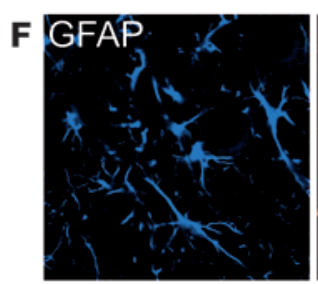

н $\mathrm{NeuN}$

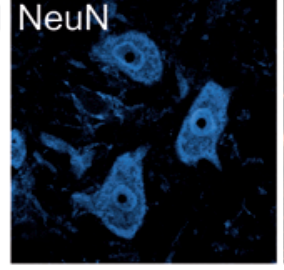

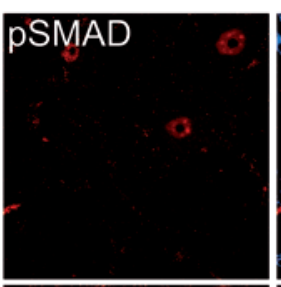

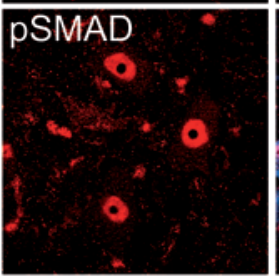

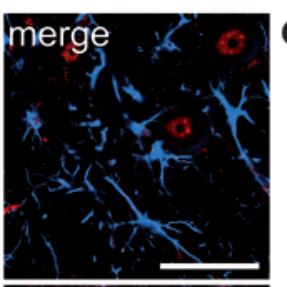

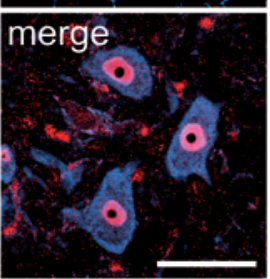

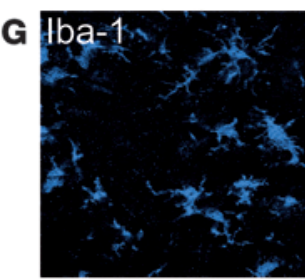

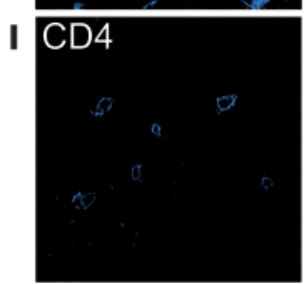

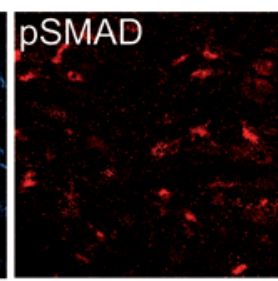
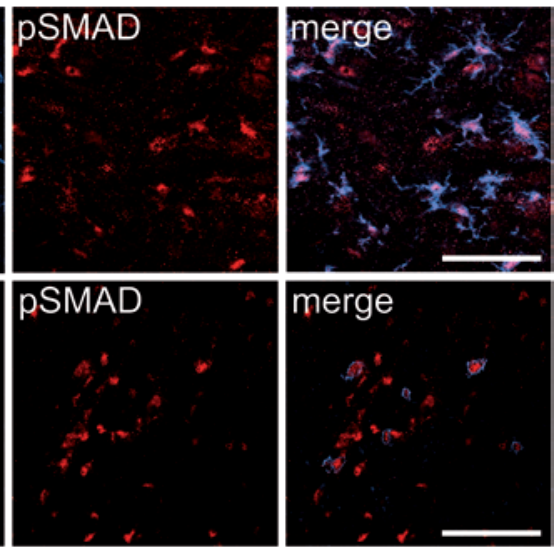

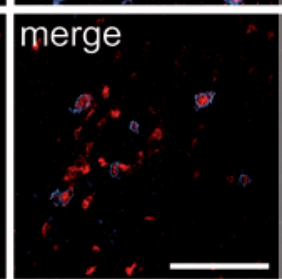

\section{Figure 4}

Downregulation of pSMAD after CA treatment. (A) In vivo bioluminescence of diseased SBE-Luc mice depicts pSMAD signaling. Mice were imaged on the indicated days after immunization. The highly increased level of pSMAD signaling in the vehicle control group (top row) is almost completely abrogated by CA treatment (bottom row). One representative mouse of each group is followed up. sr, steradian. (B and C) Statistical evaluation of the experiment shown in A. Mean intensity of bioluminescence in (B) brains and (C) spinal cords of immunized SBE-Luc mice. Mean \pm SEM of each group is shown ( $n=5$ per group). ${ }^{*} P<0.05$ (Student's $t$ test). (D) Cerebellar slices are stained for pSMAD, confirming its upregulation during EAE and its downregulation due to CA treatment. One representative slide of each group is shown. Scale bars: $100 \mu \mathrm{m}$. (E) Statistical evaluation of the experiment shown in D. pSMAD staining intensities were evaluated with MetaMorph software and normalized on the healthy control group. Statistical analysis of 6 cerebellar slices per mouse is shown $\left(n=5\right.$ mice per group; mean \pm SEM). ${ }^{*} P<0.02$ (Student's $t$ test). (F-I) Fluorescence double staining of inflamed spinal cords for pSMAD (red) and the following cell markers (blue): (F) astrocytes, (G) microglial cells, (H) neurons, and (I) CD4+ T cells. T cells show high levels of nuclear staining for pSMAD, and therefore are responsive to TGF- $\beta$, as do microglia and neurons but not astrocytes. Spinal cords are from untreated diseased mice. Scale bars: $50 \mu \mathrm{m}$.

Ang II, mice were treated daily with $1 \mathrm{mg} / \mathrm{kg}$ of the AT1R blocker candesartan (CA), starting on day 3 after immunization. TGF- $\beta$ immunohistochemistry showed that upregulation of TGF- $\beta$ during chronic EAE is blocked by treatment with CA. (Figure 3, E and F).
TGF- $\beta$ signaling in the CNS is increased Ang II dependently during chronic EAE. To confirm that Ang II-mediated induction of active TGF- $\beta$ in the CNS during chronic EAE results in the activation of endogenous TGF- $\beta$ signaling, we measured phosphorylation of 

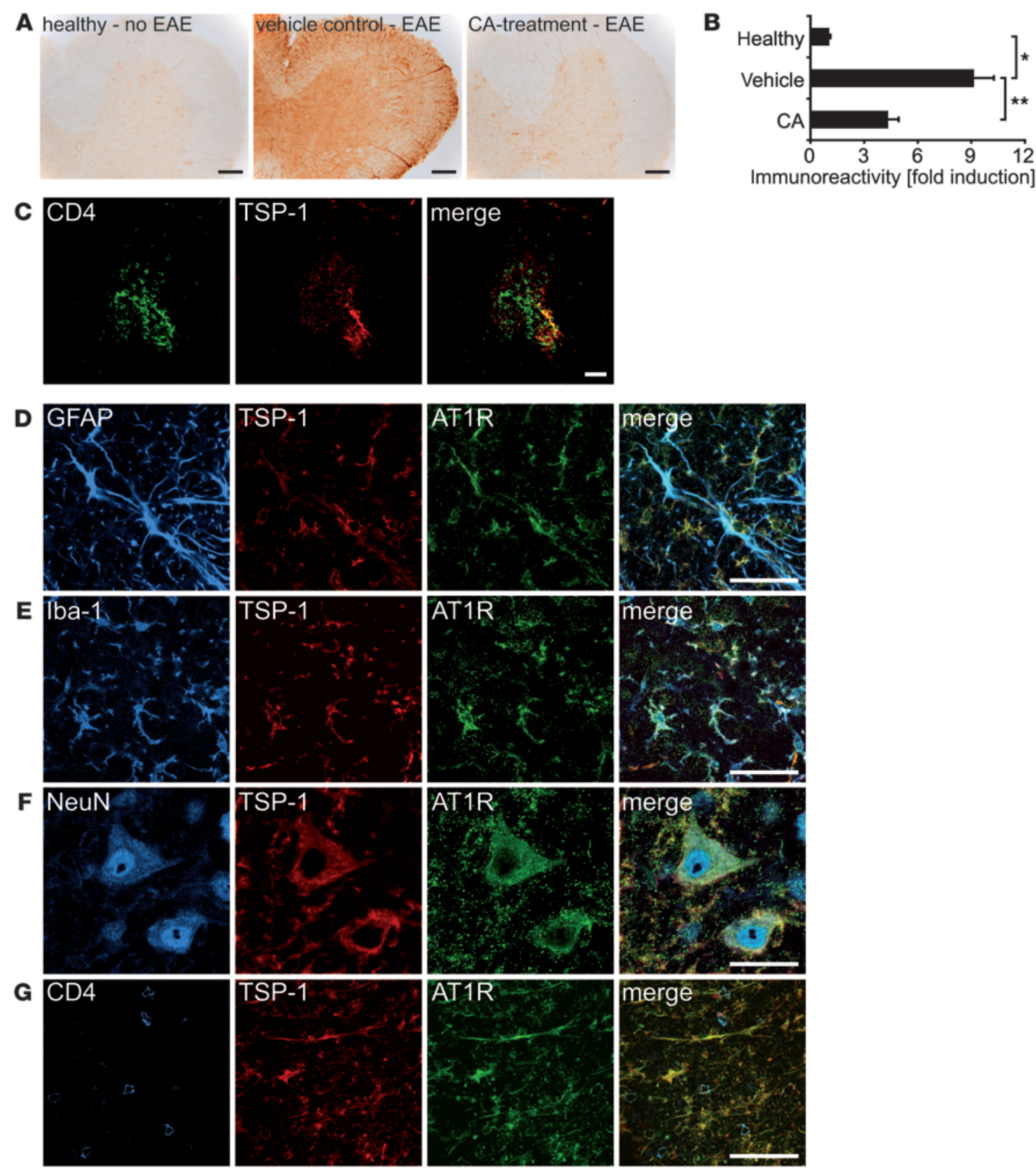

Immunoreactivity [fold induction]
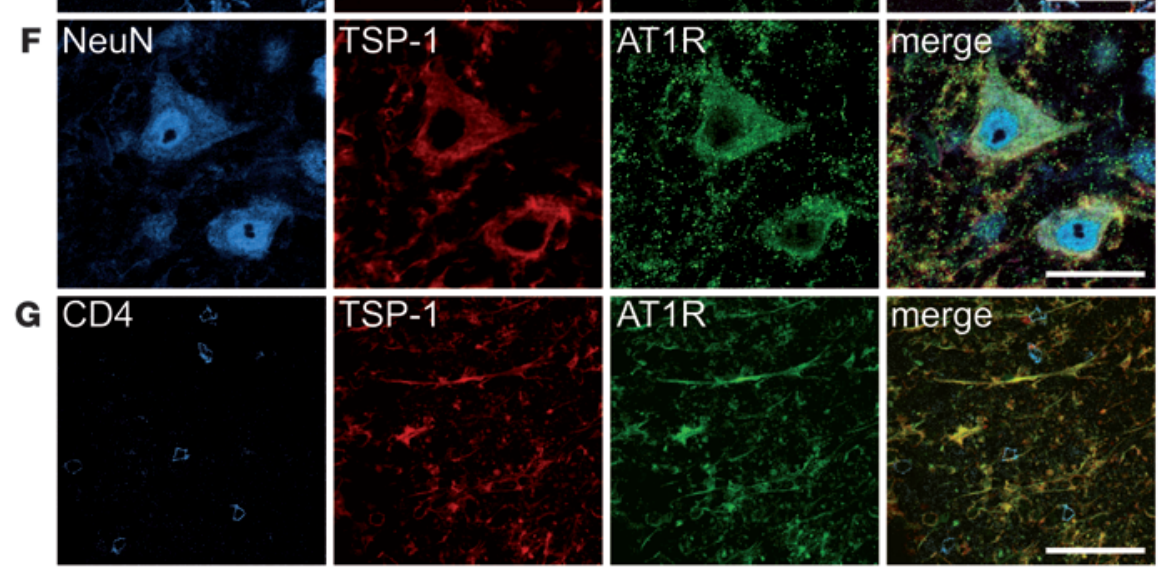

\section{Figure 5}

Ang Il drives upregulation of TSP-1 during chronic EAE. (A) Spinal cord slices stained for TSP-1. During EAE, TSP-1 is highly upregulated in the CNS compared with healthy mice. CA treatment suppresses TSP-1 expression. One representative slide of each group is shown. Scale bars: $100 \mu \mathrm{m}$. (B) Statistical evaluation of the experiment shown in A. TSP-1 staining intensities were evaluated with MetaMorph software and normalized on the healthy control group. Statistical analyses of 5 spinal cord slices per mouse are shown $\left(n=5\right.$ mice per group; mean \pm SEM). ${ }^{*} P<0.02,{ }^{* *} P<0.001$ (Student's $t$ test). (C) Fluorescence double staining of inflamed spinal cords for CD4 (green) and TSP-1 (red). TSP-1 is upregulated in the direct vicinity of CD4+ T cell infiltrates but not in CD4 ${ }^{+}$T cells itself. Scale bars: $50 \mu \mathrm{m}$. (D-G) Fluorescence triple staining for TSP-1 (red), AT1R (green), and the following specific cellular markers (blue) as well as the merge of the 3 stainings: (D) astrocytes, (E) microglial cells, (F) neurons, and (G) CD4 ${ }^{+} \mathrm{T}$ cells. The merge shows expression of both AT1R and TSP-1 in neurons, astrocytes, and microglia. Scale bars: $50 \mu \mathrm{m}$.

SMAD2/3 (pSMAD) in the CNS using in vivo bioluminescence. To this end, we immunized transgenic SMAD-binding-element-Luc (SBE-Luc) mice that carry a luciferase gene in their DNA, downstream of the $\operatorname{SBE}(34,35)$. While immunization with $\mathrm{MOG}_{35-55}$ resulted in a strong induction of pSMAD in the CNS, treatment with CA lead to its abrogation during EAE (Figure 4, A-C). Interestingly, baseline levels of PSMAD remained unaltered by CA treatment. Confirming the bioluminescence data, PSMAD immunoreactivity was decreased in $\mathrm{CNS}$ immunohistochemistries of the CA-treated group (Figure 4, D and E). In order to determine which 

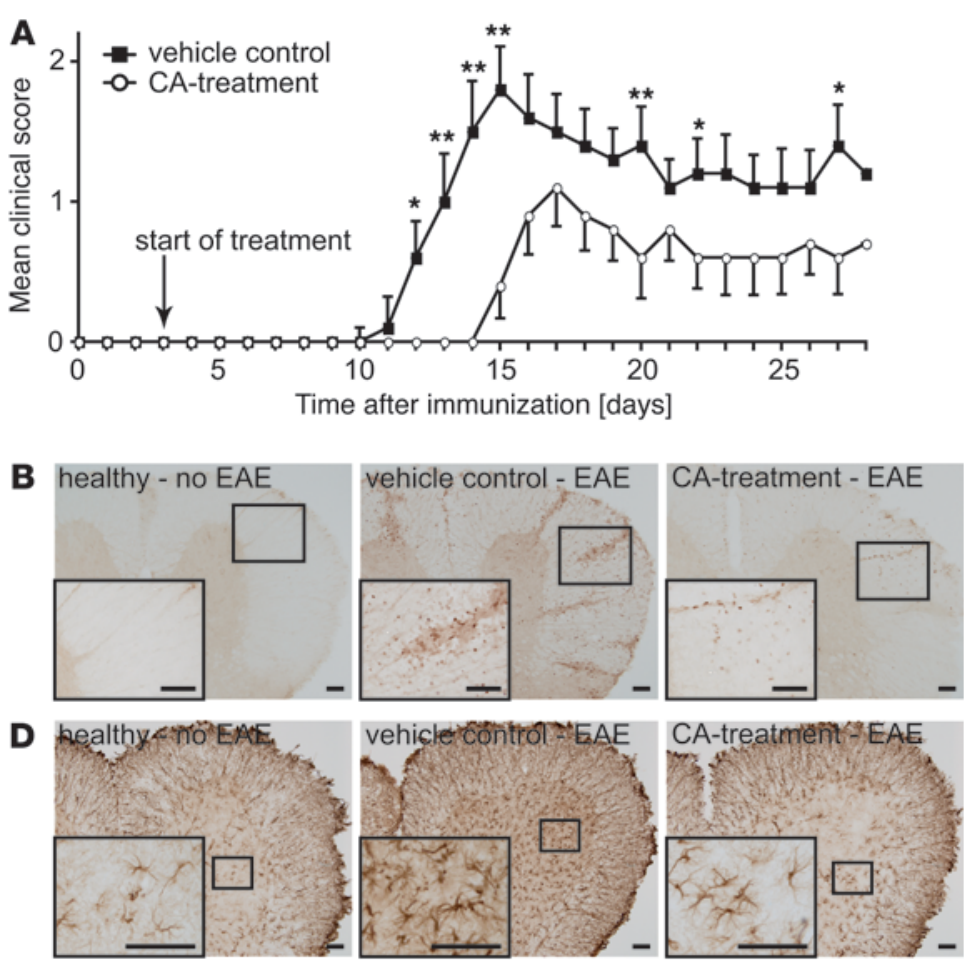

C

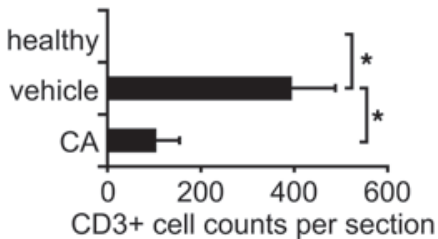

$\mathbf{E}$

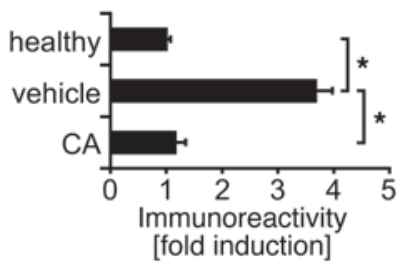

$\mathbf{F}$

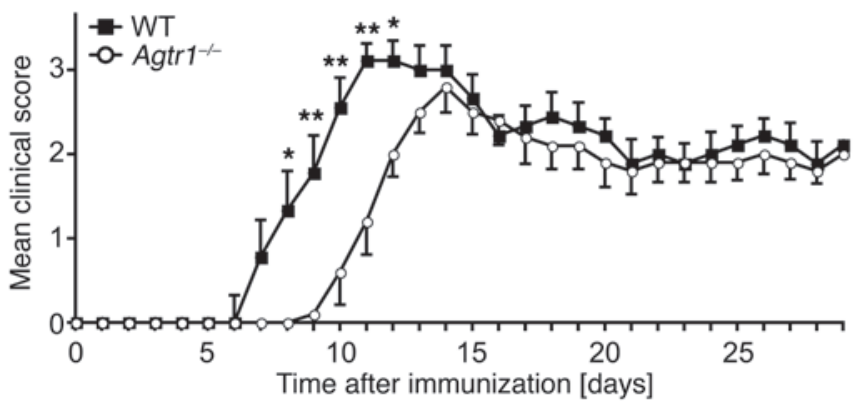

G

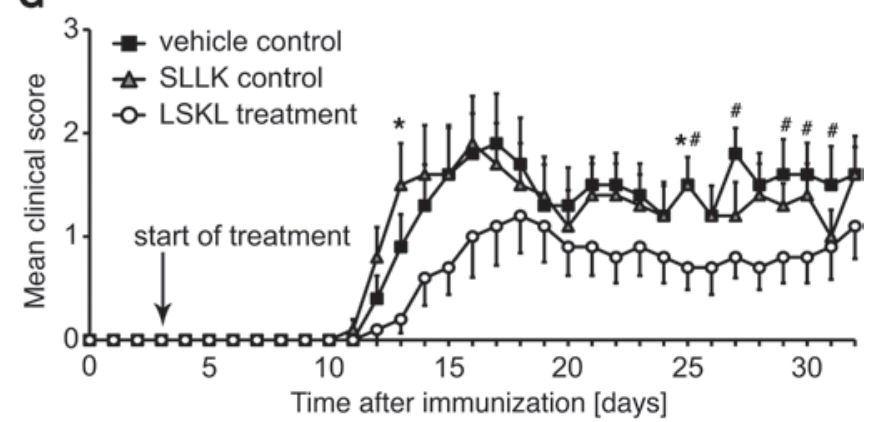

\section{Figure 6}

CA treatment delays and attenuates EAE. (A) Clinical EAE scores comparing vehicle controls with CA-treated mice. CA treatment delays and ameliorates the disease. One representative experiment of 3 independent experiments is shown ( $n=10$ females per group; mean \pm SEM). ${ }^{\star} P<0.05,{ }^{* *} P<0.02$ (Mann-Whitney $U$ test). (B) Spinal cord slices stained for CD3. CA treatment suppresses T cell infiltration into the CNS. (C) Statistical evaluation of the experiment shown in B. Count of $C D 3^{+}$cells per slide. (D) Spinal cord slices stained for GFAP. CA treatment suppresses glial activation. (E) Statistical evaluation of the experiment shown in D. GFAP staining intensities were evaluated with MetaMorph software and normalized on the healthy control group. (B and $\mathbf{D})$ One representative slide of each group is shown. Higher magnification images of the regions in the small boxes are shown in the insets. Scale bars: $50 \mu \mathrm{m}$. (C and E) Statistical analyses of 5 spinal cord slices per mouse are shown ( $n=5$ females per group; mean \pm SEM). ${ }^{*} P<0.001$ (Student's $t$ test). (F) Clinical EAE scores comparing WT C57BI/6 to Agtr1-/- mice. Onset of disease is delayed in Agtr $1^{-/-}$mice. Results are shown from 2 independent experiments $\left(n=5\right.$ females per group; mean \pm SEM). ${ }^{*}<0.05$, ${ }^{\star \star} P<0.02$ (Mann-Whitney $U$ test). (G) Clinical EAE scores comparing LSKL treatment with vehicle controls and control peptide-treated (SLLKtreated) mice. Treatment with the TSP-1 inhibitor LSKL ameliorates disease scores ( $n=10$ females per group; mean \pm SEM). ${ }^{*} P<0.05$ between LSKL- and SLLK-treated groups, ${ }^{\#} P<0.05$ between LSKL-treated and vehicle control group (Mann-Whitney $U$ test).

cells are the main responders to activated TGF- $\beta$, we costained inflamed spinal cords for PSMAD and for the specific cell markers for astrocytes (Figure 4F), microglia (Figure 4G), neurons (Figure $4 \mathrm{H}$ ), and $\mathrm{CD} 4^{+} \mathrm{T}$ cells (Figure $4 \mathrm{I}$ ). Nuclei of $\mathrm{CD} 4^{+} \mathrm{T}$ cells as well as microglia and neurons showed positive immunoreactivity for PSMAD antibodies, while those of astrocytes remained unstained. Collectively, these data indicated that endogenous Ang II activates TGF- $\beta$ signaling in the CNS cells during EAE.
TSP-1 shows a similar expression pattern during neuroinflammation. Since Ang II induced activation of TGF- $\beta$ in primary astrocytes, we next determined whether Ang II also activated TGF- $\beta$ in the CNS during chronic EAE. TSP- 1 is a known major activator of TGF- $\beta$ that has been described to be responsive to Ang II in other tissues $(20,21)$. Immunohistochemistry demonstrated a marked induction of TSP-1 in the CNS during chronic EAE. This increase was blocked by treatment with CA (Figure 5, A and B). Moreover, TSP-1 


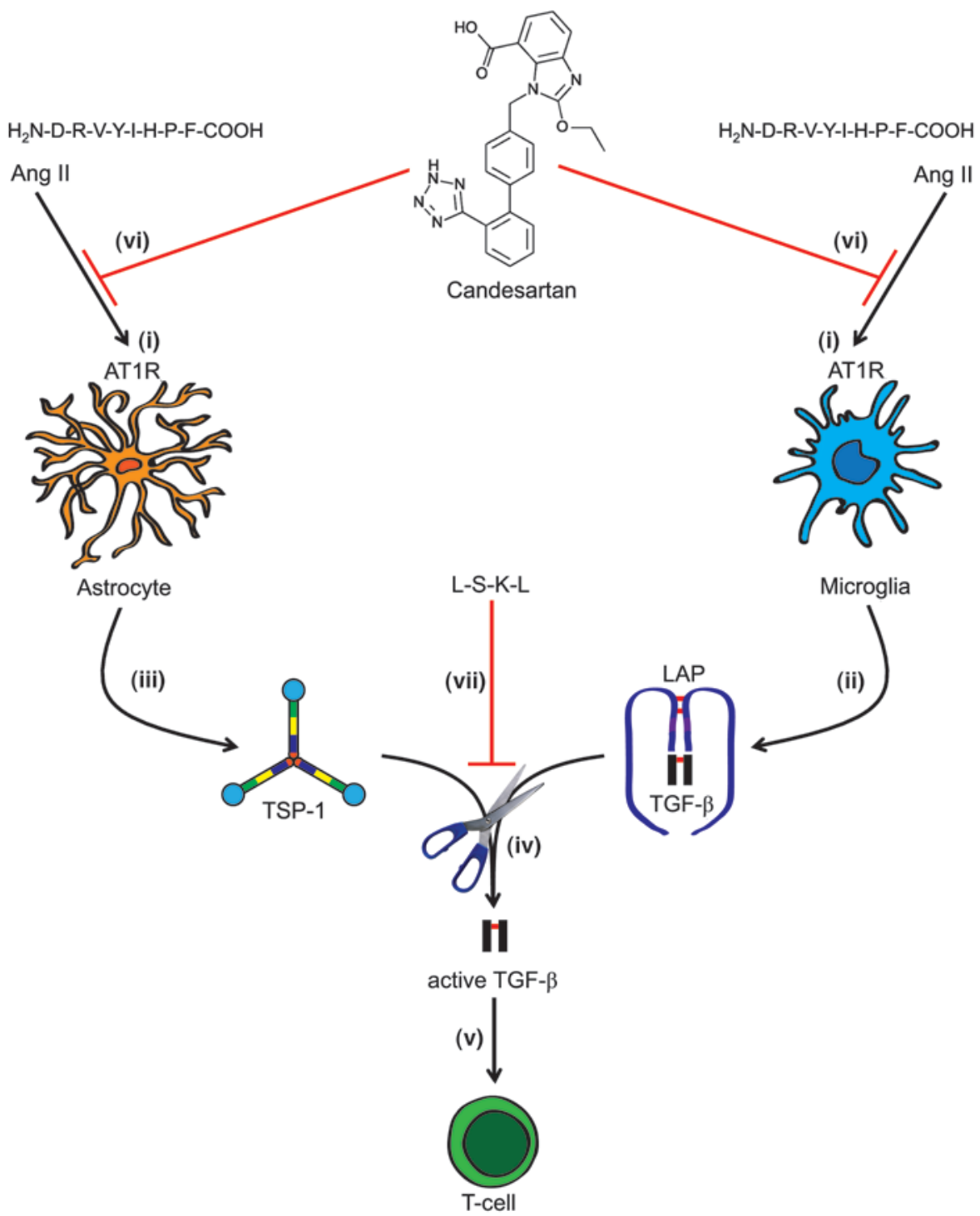

\section{Figure 7}

Schematic pathway of Ang II-TGF- $\beta$ interaction in the CNS. (i) During neuroinflammation Ang II targets astrocytes and microglia via the AT1R. (ii) Following Ang II stimulation, microglial cells increase production of TGF- $\beta$. (iii) Astrocytes in turn mainly increase their TSP-1 secretion, which (iv) cleaves off LAP and activates TGF- $\beta$. (v) More active TGF- $\beta$ in the brain creates a permissive niche in the CNS, allowing $T$ cells to obtain a more inflammatory phenotype, and therefore worsens EAE. (vi) CA inhibits this TGF- $\beta$-activating cascade at the beginning. (vii) LSKL blocks the binding between TSP- 1 and TGF- $\beta$. was expressed mainly in the areas surrounding the inflammatory infiltrate (Figure 5C). Astrocytes (Figure 5D), microglia (Figure $5 \mathrm{C}$ ), and neurons (Figure 5F) expressed high levels of TSP-1, while $\mathrm{CD}^{+} \mathrm{T}$ cells (Figure $5 \mathrm{G}$ ) produced only a little, if any, TSP-1. Collectively these data indicated that the activation of the endogenous angiotensin signaling pathway in the CNS during chronic EAE induces activation of TGF- $\beta$ via upregulation of TSP-1.

Signaling through CNS AT1R drives EAE. To analyze whether blocking signaling through AT1R is therapeutic in chronic EAE, we treated mice with CA orally at $1 \mathrm{mg} / \mathrm{kg} / \mathrm{d}$. When treatment was initiated on day 3 after immunization, we observed a delayed onset of disease for several days and an overall reduced disease severity in CA-treated mice (Figure 6A). Titration of the daily CA dose was performed up to $10 \mathrm{mg} / \mathrm{kg} / \mathrm{d}$ (data not shown), showing no difference in the level of improvement over what was observed at $1 \mathrm{mg} / \mathrm{kg} / \mathrm{d}$. One $\mathrm{mg} / \mathrm{kg} / \mathrm{d}$ is a relatively low dose, scalable to the dose used for treatment of blood pressure in humans (calculated according to FDA's guidelines; ref. 36). In contrast to the effect of CA on relapsing-remitting disease (15), which like relapsing-remitting MS is more easily treatable than chronic-progressive MS, CA treatment had no significant effect on the course of chronic-progressive EAE when administered on or after the peak of disease (Supplemental Figure 1; supplemental material available online with this article; doi:10.1172/JCI41709DS1).

Brain and spinal cord histology, after being stained with antibodies against CD3, showed a decrease of lymphocyte infiltration into the CNS in CA-treated mice, as compared with that of vehicle controls (Figure 6, B and C). Levels of GFAP, an astroglial activation marker that indicates severity of inflammation (37), were also downregulated in mice treated with CA as compared with those of vehicle controls (Figure 6, D and E).

To exclude potential nonspecific effects of CA treatment on chronic-progressive EAE, we immunized Agtr1 $1^{-/-}$mice, likewise on the C57BL/6 background, with $\mathrm{MOG}_{35-55}$ (Figure 6F). Compared with WT C57BL/6 animals, there was the same delay in disease onset in the Agtr1 $1^{-/}$mice that was observed in the CA-treated group. Following the acute phase of disease, the Agtr1 ${ }^{-/-}$mice maintained a similar disease severity as the WT control mice.

To observe changes in activation of $\mathrm{T}$ cells, we restimulated splenocytes, obtained on day 7 after immunization, with $\mathrm{MOG}_{35-55}$ 
in vitro. Antigen-specific proliferation of T cells was measured 48 hours later by $\left[{ }^{3} \mathrm{H}\right]$ thymidine uptake. Splenocytes from CA-treated mice as well as from Agtr1 $1^{-/}$animals showed significantly less proliferation than WT vehicle control mice (Supplemental Figure 2).

In order to analyze the functional significance of the previously unrecognized TSP-1-mediated pathway of Ang II-induced activation of TGF- $\beta$ in CNS-resident cells, we treated mice with the TSP-1 inhibitor LSKL, a 4-amino acid peptide that specifically blocks the binding of TSP- 1 and the large latent TGF- $\beta$ complex (LLC) (38). Treatment with LSKL resulted in a similar, delayed disease onset and an amelioration of clinical symptoms when compared with the vehicle and SLLK control groups.

Collectively, these data show that during chronic EAE, Ang II in the CNS sustains autoimmune neuroinflammation via AT1R by TGF- $\beta$ upregulation and TSP- 1 -mediated activation of TGF- $\beta$ in CNS-resident cells.

\section{Discussion}

The RAAS plays a pivotal role in the regulation of autoimmunity. We have recently reported that its inhibition with ACE inhibitors and AT1R blockers suppresses autoreactive Th1 and Th17 cells, promotes antigen-specific $\mathrm{CD}^{+} \mathrm{FoxP}^{+}$Tregs, and inhibits the canonical NF-kB1 transcription factor complex, while activating the alternative NF-кB2 pathway. We also showed that the RAAS may be critically involved in Th1/Th17-mediated autoimmune diseases and that use of an ACE inhibitor, lisinopril, and of an AT1R-inhibitor, CA, is capable of reversing relapsing-remitting EAE in SJL mice (15). Concurrently, Stegbauer et al. showed similar effects of the RAAS on immune cells, adding a special role for a reduced APC migration caused by downregulation of the chemokines CCL2, CCL3, and CXCL10 (39).

Here we focused on the role of AT1R on CNS-resident cells during chronic-progressive EAE and identified what we believe to be a novel role of Ang II during neuroinflammation. We demonstrated that astrocytes, microglia, and neurons express AT1R on high levels and are responsive to it by initiating the upregulation and activation of TGF- $\beta$. Previously, we and others had shown that AT1R is also expressed by infiltrating macrophages and epithelial cells, and it is highly upregulated in the murine and human CNS during neuroinflammation caused by $\mathrm{PLP}_{139-151^{-}}$or $\mathrm{MOG}_{35-55^{-}}$ induced autoimmunity or by viral encephalitis $(15,39)$. As shown in Supplemental Figure 3, we observed that AT1R expression is upregulated after immunization and before clinical symptoms (day 7) and is sustained throughout the peak of disease (day 14) and into disease chronicity (day 21).

TGF- $\beta$ is a highly pleiotropic and multifunctional molecule that plays pivotal roles in embryogenesis, carcinogenesis, tissue development and maintenance, and especially in the immune response. It is involved in various pathologic states as diverse as fibrosis, cancer, atherosclerosis, muscular dystrophy, and Marfan disease (16, 40, 41). Of the 3 members of the TGF- $\beta$ family (TGF- $\beta 1-$ TGF- $\beta 3$ ), TGF- $\beta 1$ is the predominant isoform expressed in the immune system (42). Almost every mammalian cell holds the capacity to secrete TGF- $\beta$ as well as respond to it via its dimerizing receptors TGF- $\beta$ RI/TGF$\beta R I I$, which then phosphorylate SMAD2/3 (19). TGF- $\beta$ influences the development, homeostasis, tolerance, and immune response of T cells (19). It is now well established that TGF- $\beta$, together with IL-2, leads to induction of $\mathrm{CD}^{+}{ }^{+} \mathrm{FoxP}^{+}$Treg cells, whereas, in combination with IL-6, it induces ROR $\gamma$ t expression and therefore causes $\mathrm{CD}^{+} \mathrm{T}$ cells to become aggressive Th17 cells (17).
Ang II-dependent overproduction of TGF- $\beta$ is a well-known pathophysiological mechanism in animal models of pulmonary, cardiac, and renal fibrosis $(2,28)$. In vitro studies demonstrate similar mechanisms in cardiac fibroblasts and smooth muscle cells as well as renal tubular and mesangial cells (29-32). We show here that, also in the CNS, total production of TGF- $\beta$ is increased by Ang II and blocked by CA treatment. Our in vitro data suggests that microglial cells are the main producers of TGF- $\beta$ in the CNS, being highly responsive to Ang II. In autoimmunity, the role of TGF- $\beta$ still remains controversial, and we must differentiate carefully under which circumstances we alter TGF- $\beta$-signaling, especially where we modulate the signaling, how we influence it, at which state of inflammation, and in which context we intervene. During the onset of EAE, high levels of TGF- $\beta$ signaling occur normally in brains and spinal cords (18). Systemic injections of TGF- $\beta$ ameliorate EAE in SJL mice $(26,27)$ and also clinical symptoms in a rat model of rheumatoid arthritis (43), while reciprocally, systemic inhibition of TGF- $\beta$ by a blocking antibody aggravates the disease (44). Knockout of TGF- $\beta$ leads to massive multifocal systemic autoimmune diseases in mice (45), and knockout mice of the TGF- $\beta$ activator TSP-1 suffer from similar albeit weaker symptoms (22). But TGF- $\beta$ does not behave like a unidirectionally immunosuppressive cytokine, as it was initially perceived. Its involvement in Th17 induction is probably only one part of the explanation. Indeed, current studies showed that blocking TGF- $\beta$ locally in the inflamed joints of the same rat model of rheumatoid arthritis could reverse inflammation and clinical symptoms (46). Its inhibition in the brain, using a synthetic inhibitor of TGF- $\beta$ RI, results in a delay of onset as well as in an amelioration of EAE (18), very similar to what we observed when treating with CA. Also TSP-1-knockout mice show a weaker course of EAE compared with WT animals (24). Inhibiting TSP-1 with the peptide LSKL is even more specific, as it particularly blocks the binding site between TSP-1 and the LLC and does not interfere with the multiple collateral functions of TSP-1 (38). Thus, we prove that TSP-1 is an important activator of TGF- $\beta$ in the brain, and its inhibition in EAE leads to delay and amelioration of the disease.

In our system, TGF- $\beta$ is blocked at the site of inflammation by influencing resident CNS cells. Using luciferase reporter mice and in vivo bioluminescence imaging as well as immunohistochemistry, we showed that CA potently inhibits TGF- $\beta$ signaling in the brains and spinal cords of mice with EAE. This approach contributes to attenuation of the immune response, especially at the onset of disease. However, when using AT1R inhibitors, the baseline of TGF- $\beta$ signaling was not altered. In fact, we were only able to reduce the immense upregulation of TGF- $\beta$ signaling that occurred during the onset phase of neuroinflammation. One could hypothesize that other molecules account for the baseline activation of TGF- $\beta$, whereas the Ang II-responsive TSP-1 is responsible for its high activation during neuroinflammation. This might explain why inhibitors of AT1R and ACE do not cause common side effects related to TGF- $\beta$ inhibition. We showed that the main paracrine responders to TGF- $\beta$ via pSMAD are T cells, neurons, and microglia but not astrocytes.

It is important to scrutinize the complex system of activation that distinguishes TGF- $\beta$ from most other cytokines (19). Briefly, the homodimer TGF- $\beta$ is secreted in its inactive form, noncovalently bound to LAP. It forms the LLC with latent TGF- $\beta$-binding protein (LTBP) and binds via LTBP to extracellular matrix proteins. TGF- $\beta$ can be activated by cleavage from the LAP, which can be easily simulated in vitro by acidification or heat. In vivo, a variety of 
molecules can act as activators of TGF- $\beta$, including proteases, such as plasmin and matrix metalloproteinases, reactive oxygen species, the integrins $\alpha_{v} \beta_{6}$ or $\alpha_{v} \beta_{8}$, and TSP-1 (19). In the CNS, TSP-1 has been described to take a special role in the context of glioma, being responsible for over $50 \%$ of TGF- $\beta$ activation caused by glioma cells (47), and its expression appears to correlate with the malignancy of gliomas (48). TSP-1 has been shown to be upregulated by Ang II in different tissues, like the heart, kidney (20), and muscle (21), in which it can be inhibited by blockade of AT1R. This is of importance in several pathologic conditions like cardiac and renal fibrosis $(2,20)$ or Marfan disease $(21)$. We show here that this signaling pathway is active in the CNS as well and therefore, AT1R inhibition with CA leads to a decrease of active TGF- $\beta$.

From our in vitro data in these experiments, it is mainly astrocytes that showed a high degree of upregulation of a TGF- $\beta$-activating agent in response to Ang II. In vivo, we demonstrated AT1R controlled upregulation of TSP-1 in the CNS during EAE by more than 9 fold. This result is supported by proteomic studies from human brain samples of chronic active MS lesions where TSP-1 is among the most highly upregulated proteins, compared with normal brain tissue (23). In turn, with CA treatment TSP-1 is suppressed very effectively, a mechanism that adequately explains the decrease of PSMAD signaling we observed. In inflamed murine spinal cords, TSP-1 is highly expressed by neurons, astrocytes, and microglia but not by the infiltrating $\mathrm{T}$ cells themselves. Moreover, we find TSP- 1 mainly in the vicinity of inflammatory infiltrates, suggesting a paracrine mechanism of TSP-1 induction. This underscores again the cross-talk between the immune system and CNS cells. The augmentation of active TGF- $\beta$ would be protective of neural tissue. However, in this context, it does not silence but rather promotes inflammation, probably caused by the distinct constellation of infiltrating lymphocytes and their cytokines.

The high coexpression of AT1R, TSP- 1 , and TGF- $\beta$ in neurons is striking and seems to be higher in the vicinity of lymphocytic infiltrates. Neurons appear to be tightly involved in this regulating mechanism via the RAAS, and their direct role must be subject to extensive further investigations.

From these experiments, we hypothesized the following events (Figure 7). During neuroinflammation, microglia and astrocytes, the main resident immunomodulatory cells in the CNS, are stimulated by Ang II via the AT1R (Figure 7, part i). In microglial cells, this initiates the production of TGF- $\beta$ (Figure 7 , part ii), whereas in astrocytes, Ang II mainly upregulates TSP-1 (Figure 7, part iii), which in turn cleaves off LAP and therefore activates latent TGF- $\beta$ (Figure 7, part iv). An increase in active TGF- $\beta$ levels in the brain creates a permissive niche in the CNS, allowing T cells to obtain a more inflammatory phenotype (Figure 7, part v), and therefore worsens EAE. CA treatment inhibits this cascade at the beginning by blocking the AT1R (Figure 7, part vi), while LSKL interferes in the binding between TSP-1 and TGF- $\beta$ and therefore blocks its activation (Figure 7, part vii).

Due to the multifunctional character of Ang II, we have to keep in mind that inhibition of TGF- $\beta$ is not the only immunomodulatory mechanism of AT1R inhibitors. Most likely it happens synergistically, with the shift from the canonical to the alternative NF-KB1 pathway and the induction of Tregs (15). Further research will be needed to elucidate how other mechanistic pathways of Ang II contribute to its T cell-dependent effect on neuroinflammation, e.g., the production of reactive oxygen species by NADPH oxidase and the induction of TNF (25) or interferon- $\gamma$ (13). Also, the unique features of neurons in this context will be of great interest and further investigations are currently in progress.
We show the clinical impact of Ang II-dependent TGF- $\beta$ activation by blocking the TGF- $\beta$-activating cascade at these 2 separate points: binding of Ang II to the AT1R and activation of TGF- $\beta$ by TSP- 1 . Both result in a delayed onset and an amelioration of the disease. The role of AT1R was confirmed by showing a similar delayed disease onset in Agtr1 $1^{-/-}$mice in comparison with WT mice. Interestingly, later clinical scores in this experiment measure up to the levels of WT mice. While humans only have 1 AT1R, mice express 2 AT1Rs (AT1Ra and AT1Rb). Only the predominant isoform, AT1Ra, is knocked out in the Agtr1 1/- EAE study, so we could hypothesize that later on in the disease, AT1Rb is able to compensate for the absence of the typical AT1Ra immunomodulating function, whereas CA constantly inhibits both isoforms. The role for the 2 murine AT1R isoforms in autoimmunity remains somewhat controversial, as Stegbauer et al. reported a slight aggravation of disease in Agtr1 $1^{--}$mice, although their data support our findings with pharmacologic AT1R inhibition (39).

Taken together, we demonstrate here extensive cross-talk among resident CNS cells, infiltrating $\mathrm{T}$ cells, and the endocrine RAAS pathway. Treatment with AT1R inhibitors delays the onset and ameliorates EAE by influencing neurons, astrocytes, and microglia to downregulate TGF- $\beta$ and TSP-1, which are normally upregulated early during inflammation. pSMAD signaling in the CNS can be dramatically inhibited by treatment with CA. We show that inhibition of TSP-1 itself is beneficial in EAE as well, indicating that TSP- 1 is the major activator of TGF- $\beta$ during EAE. TGF- $\beta$ is known to be highly multifunctional and dependent on the location and surrounding milieu in which it functions, and further studies are needed to elucidate exactly why inhibition of TGF- $\beta$ in the brain results in this perhaps counterintuitive outcome. Finally, using AT1R inhibitors as treatment for MS would be highly appealing, because they are already well-known and widely-used antihypertensive drugs, with tolerable safety profiles. These findings add to the impetus to try this promising approach for patients suffering from MS.

\section{Methods}

Animals. Female C57BL/6 mice as well as B6.129P2-Agtr1 $a^{\text {tm1Unc } / J ~ m i c e ~ w e r e ~}$ purchased from The Jackson Laboratory. SBE-luc mice were provided by Tony Wyss-Coray. 2D2 mice were provided by Vijay Kuchroo (Brigham and Women's Hospital, Boston, Massachusetts, USA). B6.129P2-Agtr1 $1 a^{\operatorname{tm} 1 U n c} / \mathrm{J}$ mice are transgenic knockout mice for AT1Ra, cloned in the 129P2 strain, and then backcrossed at least 7 times with C57BL/ 6 mice (49). Throughout the text we refer to them as Agtr1 ${ }^{-1-}$ mice. SBE-luc mice (line T9-7BA on the C57BL/6J-Tyr ${ }^{-2 J}$ genetic background, also known as "albino C57BL/6") are "responder" mice, expressing luciferase activity after the binding of pSMAD to the SBE promotor (34). Mice were screened using luciferase activity in tail biopsies, and nonresponders were sorted out. 2D2 mice are transgenic mice on a C57BL/6 background, expressing a TCR specific for $\mathrm{MOG}_{35-55}$ (50). The transgenic TCR in heterozygous mice was detected by FACS analysis of murine blood, using antibodies against CD4 and V $\beta 11$ (both from BD Pharmingen). All mice were used at 8-12 weeks of age. All animal protocols were approved by the Division of Comparative Medicine at Stanford University, in accordance with the NIH guidelines.

EAE immunization and treatments. Mice were immunized s.c. with $100 \mu \mathrm{g} /$ mouse MOG $35-55$ (Stanford Protein and Nucleic Acid Biotechnology Facility) in complete Freund's adjuvant (Difco Laboratories), containing $200 \mu \mathrm{g} /$ mouse Mycobacterium tuberculosis (strain H37 RA, Difco Laboratories). Concomitantly, $200 \mathrm{ng} / \mathrm{mouse}$ pertussis toxin was injected i.v., and 
this was repeated 48 hours later. Clinical signs of disease were scored daily according to a standard scoring system: 0 , no clinical signs; 1 , loss of tail tone; 2 , hind limb weakness; 3 , complete hind limb paralysis; 4 , hind limb and forelimb paralysis; 5 , moribund or dead.

All treatments were started on day 3 after immunization. The AT1R inhibitor CA/cilexetil (Atacand, AstraZeneca) was ground up, dissolved in $1 \mathrm{x}$ PBS, and administered once daily by oral gavage at a concentration of $1 \mathrm{mg} / \mathrm{kg} / \mathrm{d}$. Daily gavage of $1 \mathrm{x}$ PBS without drug was used as vehicle control. Then, $100 \mu \mathrm{g} / \mathrm{d} / \mathrm{mouse}$ of the 4 -amino acid peptide inhibitor of TSP-1, LSKL, or the corresponding peptide control, SLLK (both from Stanford Protein and Nucleic Acid Biotechnology Facility), were dissolved in 1x PBS and administered daily by i.p. injections.

Recall proliferation assays. For in vitro culture of activated $\mathrm{MOG}_{35-55^{-}} \mathrm{spe}-$ cific $T$ cells, immunized mice were sacrificed on day 7 after immunization. Cervical and inguinal lymph nodes were removed and mashed through a $40-\mu \mathrm{m}$ cell strainer, then washed with PBS, and centrifuged at $200 \mathrm{~g}$ and $4^{\circ} \mathrm{C}$ for 10 minutes. Cells were washed again with PBS and seeded in 96-well plates at a concentration of $5 \times 10^{5}$ cells/well in enriched RPMI containing different concentrations of $\mathrm{MOG}_{35-55}$. For measurement of proliferation, cells were pulsed after 24 hours with $5 \mu \mathrm{Ci} / \mathrm{ml}\left[{ }^{3} \mathrm{H}\right]$ methylthymidine and harvested 24 hours later.

FACS analysis. Naive or EAE spleens were harvested 15 days after immunization, and splenocytes were singularized as described above by mashing through a 40- $\mu \mathrm{m}$ cell strainer. Naive $2 \mathrm{D} 2$ splenocytes were seeded in 6-well plates at a concentration of $5 \times 10^{6}$ splenocytes $/ \mathrm{ml}$ in enriched RPMI, containing different concentrations of $\mathrm{MOG}_{35-55}$ or antibodies against $\mathrm{CD} 3 /$ CD28 for 48 hours. Cells were permeabilized using the Cytofix/Cytofix solution (BD Biosciences), according to manufacturer's instructions. Cell staining was performed according to standard protocols. After blocking Fc receptors with anti-CD16/32 (eBioscience) and with 5\% normal donkey serum (Jackson ImmunoResearch Laboratories Inc.), cells were stained with fluorescence-labeled antibodies against CD4 (clone GK1.5, eBioscience) and $\mathrm{CD} 11 \mathrm{~b}$ (clone $\mathrm{M} 1 / 70$, eBioscience) as well as with primary rabbit-derived antibodies against AT1R (Millipore) and FITC-conjugated AffiniPure $\mathrm{F}\left(\mathrm{ab}^{\prime}\right) \mathrm{x}$ fragment donkey anti-rabbit IgG (Jackson ImmunoResearch Laboratories Inc.) as secondary antibodies. All stainings were compared with corresponding isotype controls. Stained cells were run on a FACScan Flow Cytometer (BD Biosciences). Data was analyzed using WinMDI 2.9 software (Scripps).

Tissue preparation. For immunohistochemistry, mice were sacrificed on day 6 after onset of disease in the vehicle control group to ensure a significant difference in scores between the treated and the untreated group but also to catch proper disease scores in both groups. Mice were perfused with PBS. Brains, spinal cords, and spleens were fixed in freshly made $4 \%$ PFA (Sigma-Aldrich) for 24 hours and then cryoprotected in 30\% sucrose. Brains were sectioned sagittally, and spinal cords were cut transversely at $35 \mu \mathrm{m}$, using a freezing microtome (Leica Camera Inc.), and stored in cryoprotective medium at $-20^{\circ} \mathrm{C}$. Prior to staining, slides were pretreated with $0.1 \%$ triton and $0.6 \% \mathrm{H}_{2} \mathrm{O}_{2}$ and then blocked with the proper serum.

Histology and immunohistochemistry. Floating sections of cerebellum, spinal cord, and spleen were stained by standard immunoperoxidase techniques, using biotinylated secondary antibodies with ABC kits (Vector Laboratories) and DAB (Sigma-Aldrich) plus hydrogen peroxide, according to manufacturer's instructions.

Fluorescence immunohistochemistry stainings were performed using Alexa Fluor 488-, Alexa Fluor 555-, and Alexa Fluor 647-tagged secondary antibodies (Invitrogen). When using mouse anti-mouse primary antibodies, we blocked the tissue using a MOM blocking kit (Vector Laboratories). For better detection, fluorescence immunostaining for TGF- $\beta$ was enhanced with a Tyramide Signal Amplification Kit (Invitrogen), according to manufacturer's instructions.
The following primary antibodies were used: rat anti-mouse CD3 (BD Biosciences), rat anti-mouse CD4 (BD Pharmingen), mouse anti-mouse NeuN, mouse anti-human/mouse GFAP (both from Millipore), rabbit anti-mouse Iba-1 (Wako Bioproducts), rabbit anti-mouse pSMAD2/3, rabbit anti-mouse AT1R (both from Millipore), mouse anti-human/mouse TSP-1 (Neomarkers), and rabbit anti-porcine/mouse TGF- $\beta$ (Torrey Pines Biolabs).

Light microscopy was performed with a CoolSNAP HQ camera (Photometrics) mounted on an Olympus IX71 microscope (Olympus America Inc.). For confocal microscopy, we used a Zeiss LSM510 META Confocal microscope (Carl Zeiss MicroImaging). For statistical analysis of CD3 staining, CD3-positive cells were counted from 3 to 6 transverse spinal cord slices per mouse. Other DAB stainings were evaluated by measuring immunoreactivity of 3-6 stained slices per mouse, using MetaMorph software (Molecular Devices).

Bioluminescence measurement of SBE-Luc mice. SBE-Luc mice were assayed for bioluminescence intensity using an In Vivo Imaging System (IVIS, Caliper) $(34,35)$ that uses a cooled charged-coupled device (CCD) camera. Then, $50 \mathrm{mg} / \mathrm{kg}$ D-luciferin (Caliper) were injected 10 minutes before imaging. During imaging, mice were anesthetized with isoflurane. The imaging signal was quantitated as photons $/ \mathrm{s} / \mathrm{cm}^{2} /$ steradian and integrated over 5 minutes, using Living Image software (version 2.50, Caliper). For signal quantification, photons were obtained from equally sized and positioned regions of the brains and spinal cords. Twenty-four hours before immunization, baseline imaging was performed to ensure longitudinal comparison of bioluminescence. Bioluminescence was expressed as fold induction over baseline levels.

In vitro cultures of primary microglia and astrocytes. Microglia and astrocytes were prepared according to a protocol by Ousman et al. (51). Briefly, meninges were removed from cerebral cortices of 1- to 3-day-old mice. Next, the cortices were placed in complete DMEM (Invitrogen), containing $10 \%$ fetal bovine serum, penicillin-streptomycin, L-glutamine, and sodium-pyruvate (all from Invitrogen), minced, vortexed at high speed for 1 minute, and passed through a 18.5-gauge needle. The ground-up cortices were filtered successively through sterile $80-\mathrm{nm}$ and 11-nm filters (Millipore). Cells from one brain were seeded in complete DMEM into one $75-\mathrm{cm}^{2}$ tissue culture flask and placed in a $5 \%$ aerated $\mathrm{CO}_{2}$ incubator at $37^{\circ} \mathrm{C}$. Media was changed every third day. Upon confluence, cells were trypsinized (Invitrogen), split and reseeded with onethird of the previous density, and then cultured again until confluence. Then, microglia was shaken off using an orbital shaker for 30 minutes. Microglia was seeded in 6-well plates at a concentration of $10^{5}$ microglial cells/well, and media was changed after 12 hours for stimulation. Astrocytes were trypsinized after separation from the microglial cells and seeded in 6-well plates as well at the same concentration. Media was changed, and astrocytes were stimulated after additional 48 hours.

Cell culture stimulation. Microglia and astrocytes were washed with 1x PBS 3 times and then stimulated for 48 hours or 72 hours, respectively, in new serum-free DMEM (containing penicillin-streptomycin, L-glutamine, and sodium-pyruvate), with 500 pM Ang II (Stanford Protein and Nucleic Acid Biotechnology Facility) and $10 \mu \mathrm{M}$ losartan (Fluka/Sigma-Aldrich). The specific AT1R inhibitor losartan was used in vitro, because unlike CA/cilexetil, losartan is available as an already biologically active drug and does not have to be metabolized from a prodrug. The best time points and concentrations of reagents have been determined previously.

After stimulation, supernatants were taken up, spun down at $4{ }^{\circ} \mathrm{C}$ and $8,600 \mathrm{~g}$ for 5 minutes to remove debris, and divided into 2 parts for measurement of total and active TGF- $\beta$.

TGF- $\beta$ measurement. The amount of active TGF- $\beta$ was measured using MFB-F11 cells, a fibroblast cell line derived from TGF- $\beta$-knockout mice and stably transfected with the SBE-SEAP reporter (33). The amount of SEAP is directly proportional to the amount of active TGF- $\beta$ in the medium. 
MFB-F11 cells were seeded in complete DMEM at a concentration of $2 \times 10^{4}$ cells into flat bottomed 96 -well plates. Twenty-four hours later, cells were washed 3 times with PBS and then covered with supernatants from cultured primary microglia or astrocytes for additional 24 hours. For measurement of total TGF- $\beta$, supernatants were acidified with $6 \mathrm{~N} \mathrm{HCl}$ for 10 minutes and then neutralized with $6 \mathrm{~N} \mathrm{NaOH}$ right before application. Active TGF- $\beta$ was measured from untreated supernatants. Samples were measured in triplicates. SEAP activity was measured using the Great EscAPe SEAP Reporter System 3 (BD Biosciences), according to the manufacturer's instructions, with an Lmax plate photometer (Molecular Devices).

Statistics. Results were assessed by applying the Student's $t$ test statistics to the experimental data obtained in vitro. In vivo data was statistically evaluated using the Mann-Whitney $U$ test. $P$ values of less than 0.05 were considered significant. Statistic details are indicated in the respective figure legends.

\section{Acknowledgments}

The Steinman laboratory is supported by the NIH and by the National Multiple Sclerosis Society, by the Helmholtz-Foundation (VH-NG-306 to M. Platten), and by the German National Academic Foundation (Studienstiftung des deutschen Volkes to T.V. Lanz).

Received for publication November 10, 2009, and accepted in revised form May 26, 2010.

Address correspondence to: Lawrence Steinman, Department of Neurology and Neurological Studies, Beckman Center, Room B002, 279 Campus Drive, Stanford, California 94305-5316, USA. Phone: 650.725.6401; Fax: 650.725.0627; E-mail: steinman@stanford.edu.
1. Bader M, Ganten D. Update on tissue renin-angiotensin systems. J Mol Med. 2008;86(6):615-621.

2. Sun Y, Zhang JQ, Zhang J, Ramires FJ. Angiotensin II, transforming growth factor-beta1 and repair in the infarcted heart. J Mol Cell Cardiol. 1998;30(8):1559-1569.

3. Nagashio Y, et al. Angiotensin II type 1 receptor interaction is an important regulator for the development of pancreatic fibrosis in mice. Am J Physiol Gastrointest Liver Physiol. 2004;287(1):G170-G177.

4. Sarlos S, Wilkinson-Berka JL. The renin-angiotensin system and the developing retinal vasculature. Invest Ophthalmol Vis Sci. 2005;46(3):1069-1077.

5. Morimoto S, Cassell MD, Sigmund CD. The brain renin-angiotensin system in transgenic mice carrying a highly regulated human renin transgene. Circ Res. 2002;90(1):80-86.

6. Wilkinson-Berka JL, Kelly DJ, Rong P, Campbell DJ, Skinner SL. Characterisation of a thymic reninangiotensin system in the transgenic $\mathrm{m}($ Ren-2) 27 rat. Mol Cell Endocrinol. 2002;194(1-2):201-209.

7. Nahmod KA, et al. Control of dendritic cell differentiation by angiotensin II. FASEB J. 2003; 17(3):491-493

8. Potter DD, Sobey CG, Tompkins PK, Rossen JD, Heistad DD. Evidence that macrophages in atherosclerotic lesions contain angiotensin II. Circulation. 1998;98(8):800-807.

9. Rasini E, et al. Angiotensin II type 1 receptor expression on human leukocyte subsets: a flow cytometric and RT-PCR study. Regul Pept. 2006;134(2-3):69-74.

10. Hammoud RA, Vaccari CS, Nagamia SH, Khan $\mathrm{BV}$. Regulation of the renin-angiotensin system in coronary atherosclerosis: a review of the literature. Vasc Health Risk Manag. 2007;3(6):937-945.

11. Nabah YN, et al. Angiotensin II induces neutrophil accumulation in vivo through generation and release of CXC chemokines. Circulation. 2004;110(23):3581-3586.

12. Dalbeth N, Edwards J, Fairchild S, Callan M, Hall FC. The non-thiol angiotensin-converting enzyme inhibitor quinapril suppresses inflammatory arthritis. Rheumatology (Oxford). 2005;44(1):24-31.

13. Sagawa K, Nagatani K, Komagata Y, Yamamoto K. Angiotensin receptor blockers suppress antigen-specific T cell responses and ameliorate collagen-induced arthritis in mice. Arthritis Rheum. 2005;52(6):1920-1928.

14. Okunuki Y, et al. Suppression of experimental autoimmune uveitis by angiotensin II type 1 receptor blocker telmisartan. Invest Ophthalmol Vis Sci. 2009;50(5):2255-2261.

15. Platten $\mathrm{M}$, et al. Blocking angiotensin-converting enzyme induces potent regulatory $\mathrm{T}$ cells and modulates TH1- and TH17-mediated autoimmunity. Proc Natl Acad Sci U S A. 2009;106(35):14948-14953.

16. Blobe GC, Schiemann WP, Lodish HF. Role of transforming growth factor beta in human disease. NEngl J Med. 2000;342(18):1350-1358.
17. Bettelli E, Oukka M, Kuchroo VK. T(H)-17 cells in the circle of immunity and autoimmunity. Nat Immunol. 2007;8(4):345-350.

18. Luo J, et al. Glia-dependent TGF-beta signaling, acting independently of the TH17 pathway, is critical for initiation of murine autoimmune encephalomyelitis. J Clin Invest. 2007;117(11):3306-3315.

19. Li MO, Flavell RA. TGF-beta: a master of all T cell trades. Cell. 2008;134(3):392-404.

20. Zhou Y, Poczatek MH, Berecek KH, MurphyUllrich JE. Thrombospondin 1 mediates angiotensin II induction of TGF-beta activation by cardiac and renal cells under both high and low glucose conditions. Biochem Biophys Res Commun. 2006;339(2):633-641.

21. Cohn RD, et al. Angiotensin II type 1 receptor blockade attenuates TGF-beta-induced failure of muscle regeneration in multiple myopathic states. Nat Med. 2007;13(2):204-210.

22. Crawford SE, et al. Thrombospondin-1 is a major activator of TGF-beta1 in vivo. Cell. 1998; 93(7):1159-1170.

23. Han MH, et al. Proteomic analysis of active multiple sclerosis lesions reveals therapeutic targets. Nature. 2008;451(7182):1076-1081.

24. Yang K, et al. Deficiency of thrombospondin-1 reduces Th17 differentiation and attenuates experimental autoimmune encephalomyelitis. J Autoimmun. 2009;32(2):94-103.

25. Hoch NE, et al. Regulation of T-cell function by endogenously produced angiotensin II. Am J Physiol Regul Integr Comp Physiol. 2009;296(2):R208-R216.

26. Johns LD, Flanders KC, Ranges GE, Sriram S. Successful treatment of experimental allergic encephalomyelitis with transforming growth factor-beta 1. J Immunol. 1991;147(6):1792-1796.

27. Kuruvilla AP Shah R, Hochwald GM Liggitt HD, Palladino MA Thorbecke GJ. Protective effect of transforming growth factor beta 1 on experimental autoimmune diseases in mice. Proc Natl Acad Sci U S A. 1991;88(7):2918-2921.

28. Datta PK, Moulder JE, Fish BL, Cohen EP, Lianos EA. TGF-beta 1 production in radiation nephropathy: role of angiotensin II. Int J Radiat Biol. 1999;75(4):473-479.

29. Kagami S, Border WA, Miller DE, Noble NA. Angiotensin II stimulates extracellular matrix protein synthesis through induction of transforming growth factor-beta expression in rat glomerular mesangial cells. J Clin Invest. 1994;93(6):2431-2437.

30. Lee AA, Dillmann WH, McCulloch AD, Villarreal FJ. Angiotensin II stimulates the autocrine production of transforming growth factor-beta 1 in adult rat cardiac fibroblasts. $\mathrm{J} \mathrm{Mol} \mathrm{Cell} \mathrm{Cardiol.}$ 1995;27(10):2347-2357

31. McKay S, de Jongste JC, Saxena PR, Sharma HS. Angiotensin II induces hypertrophy of human airway smooth muscle cells: expression of transcription factors and transforming growth factor-beta1.
Am J Respir Cell Mol Biol. 1998;18(6):823-833.

32. Wolf G, Mueller E, Stahl RA, Ziyadeh FN. Angiotensin II-induced hypertrophy of cultured murine proximal tubular cells is mediated by endogenous transforming growth factor-beta. J Clin Invest. 1993;92(3):1366-1372.

33. Tesseur I, Zou K, Berber E, Zhang H, Wyss-Coray T. Highly sensitive and specific bioassay for measuring bioactive TGF-beta. BMC Cell Biol. 2006;7:15.

34. Lin AH, et al. Global analysis of Smad2/3-dependent TGF-beta signaling in living mice reveals prominent tissue-specific responses to injury. J Immunol. 2005;175(1):547-554.

35. Luo J, Lin AH, Masliah E, Wyss-Coray T. Bioluminescence imaging of Smad signaling in living mice shows correlation with excitotoxic neurodegeneration. Proc Natl Acad Sci U S A. 2006;103(48):18326-18331.

36. F.D.A. U.S. Department of Health and Human Services, Center for Drug Evaluation and Research (CDER), ed. Estimating the Maximum Safe Starting Dose in Initial Clinical Trials for Therapentics in Adult Healthy Volunteers. Rockville, Maryland, USA: US Food and Drug Administration; 2005.

37. Luo J, Ho P, Steinman L, Wyss-Coray T. Bioluminescence in vivo imaging of autoimmune encephalomyelitis predicts disease. J Neuroinflammation. 2008;5:6.

38. Ribeiro SM, Poczatek M, Schultz-Cherry S, Villain $\mathrm{M}$, Murphy-Ullrich JE. The activation sequence of thrombospondin-1 interacts with the latencyassociated peptide to regulate activation of latent transforming growth factor-beta. J Biol Chem. 1999;274(19): 13586-13593.

39. Stegbauer J, et al. Role of the renin-angiotensin system in autoimmune inflammation of the central nervous system. Proc Natl Acad Sci U S A. 2009;106(35):14942-14947.

40. Massague J, Gomis RR. The logic of TGFbeta signaling. FEBS Lett. 2006;580(12):2811-2820.

41. Dietz HC, Loeys B, Carta L, Ramirez F. Recent progress towards a molecular understanding of Marfan syndrome. Am J Med Genet C Semin Med Genet. 2005;139C(1):4-9.

42. Letterio JJ, Roberts AB. Regulation of immune responses by TGF-beta. Annu Rev Immunol. 1998;16:137-161.

43. Brandes ME, Allen JB, Ogawa Y, Wahl SM. Transforming growth factor beta 1 suppresses acute and chronic arthritis in experimental animals. J Clin Invest. 1991;87(3):1108-1113.

44. Thorbecke GJ Shah R, Leu CH Kuruvilla AP, Hardison AM Palladino MA. Involvement of endogenous tumor necrosis factor alpha and transforming growth factor beta during induction of collagen type II arthritis in mice. Proc Natl Acad Sci U S A. 1992;89(16):7375-7379.

45. Yaswen L, et al. Autoimmune manifestations in the transforming growth factor-beta 1 knockout mouse. Blood. 1996;87(4):1439-1445.

46. Wahl SM, Allen JB, Costa GL, Wong HL, Dasch JR. 
Reversal of acute and chronic synovial inflammation by anti-transforming growth factor beta. J Exp Med. 1993;177(1):225-230.

47. Sasaki A, Naganuma H, Satoh E, Kawataki T, Amagasaki K, Nukui H. Participation of thrombospondin-1 in the activation of latent transforming growth factor-beta in malignant glioma cells. Neurol Med Chir (Tokyo). 2001;41(5):253-258; discussion 258-259.
48. Kawataki T, Naganuma H, Sasaki A, Yoshikawa $H$, Tasaka K, Nukui H. Correlation of thrombospondin-1 and transforming growth factor-beta expression with malignancy of glioma. Neuropathology. 2000;20(3):161-169.

49. Ito $M$, et al. Regulation of blood pressure by the type $1 \mathrm{~A}$ angiotensin II receptor gene. Proc Natl Acad Sci U S A. 1995;92(8):3521-3525.

50. Bettelli E, Pagany M, Weiner HL, Linington C,
Sobel RA, Kuchroo VK. Myelin oligodendrocyte glycoprotein-specific $\mathrm{T}$ cell receptor transgenic mice develop spontaneous autoimmune optic neuritis. J Exp Med. 2003;197(9):1073-1081.

51. Ousman SS, Wang J, Campbell IL. Differential regulation of interferon regulatory factor (IRF)-7 and IRF-9 gene expression in the central nervous system during viral infection. J Virol. 2005;79(12):7514-7527. 